\title{
Experiences in the implementation of the Safe Surgery Verification Checklist at the National Hospital Arzobispo Loayza, 2014-2016
}

\author{
Ana Gonzales Espinozaa ${ }^{\mathrm{a}}$, Monica Meneses La Riva ${ }^{\mathrm{b},}$ \\ a Patient Safety, National Hospital Arzobispo Loayza, Peru \\ ${ }^{b}$ Dirección de Investigación, Universidad Cesar Vallejo - Lima Norte. \\ mmeneseslariva@yahoo.com
}

\section{Resumen}

El objetivo fue determinar las experiencias en la implementación de la Lista de Verificación de Cirugía Segura (LVCS) en el Hospital Nacional Arzobispo Loayza 2014- 2016. El estudio fue descriptivo, retrospectivo de revisión documental de 2,466 Historias clínicas con Hoja de aplicación LVCS. Se utilizaron dos instrumentos que evaluaron el cumplimiento de la LVCS a través de una matriz de control para cotejar 20 ítems en las tres fases de ejecución, también se aplicó una encuesta al personal (Cirugía, Anestesia y Enfermería) que labora en Centro quirúrgico. Se identificaron los factores que limitan la aplicación de la LVCS previamente asumiendo las consideraciones éticas respectivas. El cumplimiento de la LVCS alcanzó un 93\% y el incumplimiento de mayor frecuencia en la fase Entrada referido a la valoración de riesgo de hemorragia $>500 \mathrm{~mL}(36 \%)$. En la fase Pausa se verifica la profilaxis antibiótica administrada en los últimos 60 minutos (39\%) del total de omisiones. En la fase salida revisa los aspectos críticos de la recuperación y el tratamiento en PO inmediato (42\%). Los factores que limitan la aplicación de la LVCS fueron: La falta de motivación del personal (34\%), desconocimiento, falta de entrenamiento y problemas en la distribución de personal/tareas (10\% respectivamente). En conclusión se evidencia un alto nivel de cumplimiento, sin embargo la calidad del registro evidencia un pobre involucramiento de responsabilidad interdisciplinaria debilitando el entorno seguro para el paciente quirúrgico.

Palabras clave: Cirugía segura, lista de verificación, LVCS.

\begin{abstract}
The objective was determining the experiences in the implementation of the Safe Surgery Verification Checklist (SSVC) in the National Hospital Arzobispo Loayza in period 2014-2016. The Methodology was descriptive, retrospective study of a documentary review of 2,466 clinical histories with the SSVC application sheet. It was used two instruments that evaluated the compliance of the SSVC through a control matrix to check 20 items in the three phases of execution with correct filling and omission, also a survey was applied to the personnel (Surgery, Anesthesia and Nursing). Its work in Surgical Center where the factors that limit the application of the SSVC were identified, previously assuming the respective ethical considerations. Results were compliance with the SSVC reached $93 \%$ and the most frequent noncompliance in the Entry phase referred to the risk assessment of bleeding $>500 \mathrm{~mL}(36 \%)$. In the Pause phase the item verifies the antibiotic prophylaxis administered in the last 60 minutes (39\%) of the total of omissions. In the exit phase the item review the critical aspects of recovery and treatment in immediate PO (42\%). The factors that limit the application of the SSVC were: Lack of staff motivation (34\%), ignorance, lack of training and problems in the distribution of personnel / tasks (10\% respectively). In conclusions a high level of compliance is evidenced, however, the quality of the registry shows a poor involvement of interdisciplinary responsibility, weakening the safe environment for the surgical patient.
\end{abstract}

Keywords: Safe surgery, Verification checklist SSVC. 


\section{GHM \\ \& Medicine}

Vol. 2, $\mathrm{N}^{\circ}$ 1, 2018

Copyright @ 2018, CINCADER.

ISSN 2523-9511
Journal of Global Health

\section{Introduction}

At present, the World Health Organization (WHO) has been making strenuous efforts so that health professionals in their daily work, get involved in working on good health practices. The services provided to the patient require a safe environment, both for the professionals themselves and for the patients, in order to avoid risks and complications in health. This implies to consider use of the measures of biosafety, rounds of safety in the hospital area and the application of the checklist among others [1]. It should be noted that the WHO statistics report that there are approximately 234 million major surgery operations per year and the margin of error is between $3 \%$ and $25 \%$ of complications, which cause disabilities or prolong the hospitalization of patients withstand postoperative complications. Likewise, it is estimated that mortality rates attributable to major surgery interventions range from $0.4 \%$ to $10 \%$, depending on the complexity of the operation and the hospital environment. According to the corresponding impact assessments, at least one million patients die each year during or after an operation, other international studies from developed countries, such as the European Commission, confirm the magnitude and significance of the problem, because the statistical information clearly reveals the high percentages of complications and deaths, in scheduled or emergency surgical interventions. In 2004, the WHO launched the "Alliance for Patient Safety" proposal, carrying out an exhaustive analysis of the world situation. It concluded the need to create safe environments, as a consequence of this exhausting situation of public health and that entails ensure the best conditions to promote actions and the application of tools and recommendations to improve patient safety worldwide [2].

The study of the Ministry of Health and Social Policy of Madrid "Prevalence of adverse effects in hospitals in Latin America developed in five countries (Mexico, Peru, Argentina, Costa Rica and Colombia)", was included a sample of 11,555 patients admitted to 58 hospitals and where they indicate that the frequency of Adverse Events (AE) was $11.85 \%$ and the possibility of prevention was $60 \%$. In addition, the AEs were related to care in $13.27 \%$, with the use of medication in $8.23 \%$, with nosocomial infections in $37.14 \%$, with some procedure in $28.69 \%$ and with the diagnosis in $6.15 \%$ [3].

The surgical interventions are procedures that are usually given as a practical part and involve mechanical manipulation of anatomical structures with a medical purpose, whether diagnostic, therapeutic or prognostic. Surgical procedures that require knowledge, abilities and skills, [...] becoming the SSVC an essential instrument that allows the multidisciplinary team to meet quality standards to avoid and mitigate risks [4].

The safe provision of health services requires a change of paradigms of health professionals, being closely linked to teamwork and the principles of values of responsibility. It should be emphasized that in order to promote safe surgical environments, it is necessary to use all the procedures of the safe surgery checklist in everyday life, as the tool that will become an opportunity for the health team, by reducing the occurrence of failures, errors, adverse results and facilitate analyzing and generating new knowledge that will help improve teamwork in this area. Hence the importance of care risk management, as an element that allows identifying the factors that contribute to the occurrence of incidents related to patient safety, as well as improving the culture of safety and identification of human and organizational factors [3,4].

Some studies carried out in Peru on patient safety reveal that there is an urgent need to strengthen a safety culture in private and public healthcare institutions to guarantee the quality of services they provide to users $[5,6,7]$.

The importance of this proposed study is to evaluate the experience gained in a public institution on the implementation of the Safe Surgery Verification Checklist and identify the factors that limit its application, in order to analyze and understand the adherence behavior of the check list of safe surgery in the surgical areas and also, propose corrective measures and improvement plans that guarantee safe environments and the quality of the services offered to the patient.

\section{Methodology}

Descriptive, retrospective study of documentary review of 2,466 clinical histories with SSVC application sheet from 2014 to 2016. The study was conducted at the National Hospital Arzobispo Loayza, located in block 8 of Avenida Alfonso Ugarte, Breña, institution categorized as III-1 Level of national reference and that has 735 hospital beds of which $42 \%$ (310 beds) correspond to the surgical area. At the institutional level there are 19 operating rooms distributed in 6 surgical centers and the estimated population was obtained by counting the results obtained in the quarterly monitoring cuts distributed as follows. 


\section{GHM}

Vol. 2, $\mathrm{N}^{\circ} 1,2018$

Copyright @ 2018, CINCADER.

ISSN 2523-9511

\section{Journal of Global Health}

\& Medicine

Table 1. Amount of clinical histories by years 2014 to 2016 .

\begin{tabular}{cc}
\hline YEAR & $\mathbf{N}^{\circ}$ de $\mathbf{C H}$ \\
\hline 2014 & 613 \\
2015 & 948 \\
2016 & 905 \\
\hline
\end{tabular}

The SSVC format for institutional use (designed by the WHO and approved with RM No. 308-2010 / MINSA) was used as an instrument, which consists of three parts and 20 items distributed in 3 phases: Entry with 7 items (before administration of anesthesia), Pause with 8 items (before the cutaneous incision) and Exit with 5 items (before the patient leaves the operating room). An Excel format was designed which allowed recording general data such as: Clinical history number, pavilion, bed, operative diagnosis, surgery date, entry, pause, departure, coordinator, surgeon, anesthesiologist, nurse and a last column for observations.

In the input, pause and exit phase, the omitted item number was registered and if it was correctly registered, a check was placed. To determine the administration of the prophylactic, the information was cross-checked between the item marking, the prescription registered in the Medical Therapy Sheet and the registration of the Nursing Kardex administration.

To measure the compliance level was calculated through the sum of items with correct answer in each format, multiplied by 100 and divided by the total number of items (20), this allowed obtaining the level of compliance. Based on this result, the scale was taken into account considering a score of 91 to $100 \%$ GOOD, from 85 to $90 \%$ IN PROCESS and less than $85 \%$ TO IMPROVE. To assess the factors that influence the multidisciplinary team for the application of the SSVC was self-administered to the occupational groups of surgery, anesthesiology and nursing, respectively.

\section{Results}

The application of the Surgical Safety Checklist with a sustained progress from 90 to $95 \%$, so it is categorized GOOD; and on the other hand an application omission is credited starting from $10 \%$ and decreasing to $5 \%$. See Figure 1.

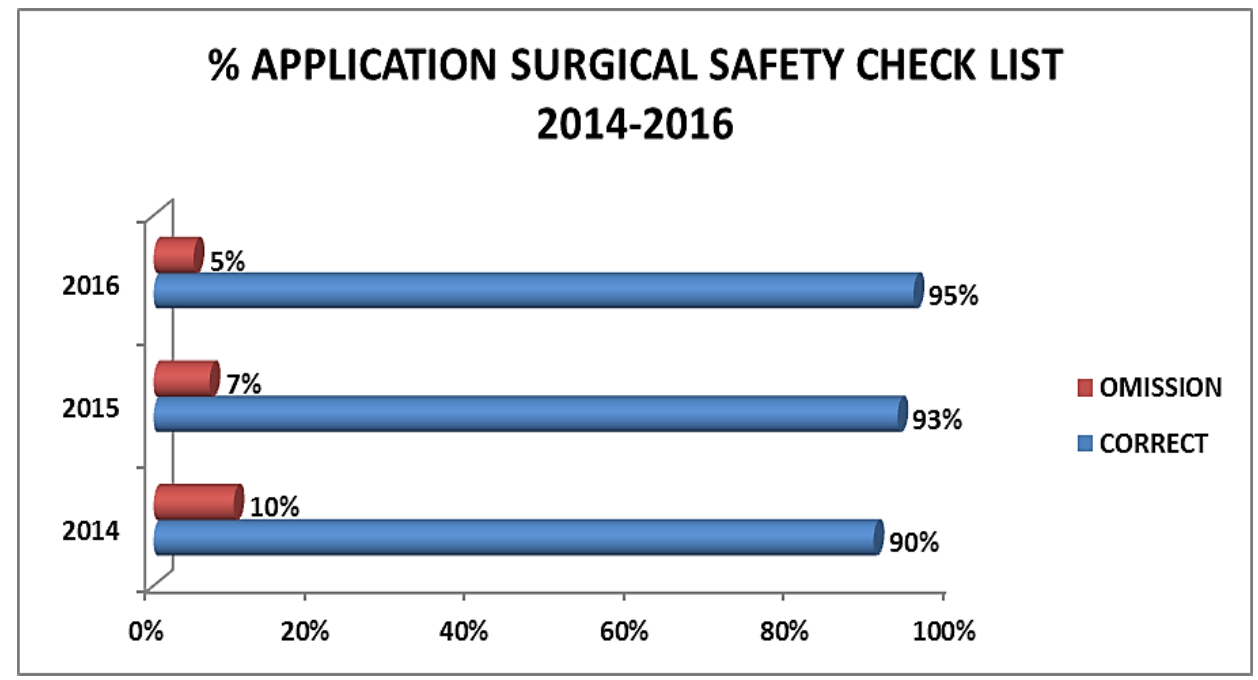

Figure 1. The Surgical Safety Checklist, 2014-2016.

From 2466 formats, 56.3\% (1389 CH) achieve the AVERAGE based on a correct and complete record, showing a sustained upward curve during the years 2014 to 2016. See Figure 2. 


\section{GHM}

Journal of Global Health

Vol. 2, $\mathrm{N}^{\circ} 1,2018$

\& Medicine
Copyright (c) 2018, CINCADER.

ISSN 2523-9511
A publication of

\section{CINGADER}

Centre of Research and Training for

Regional Development Online at www.journals.cincader.org

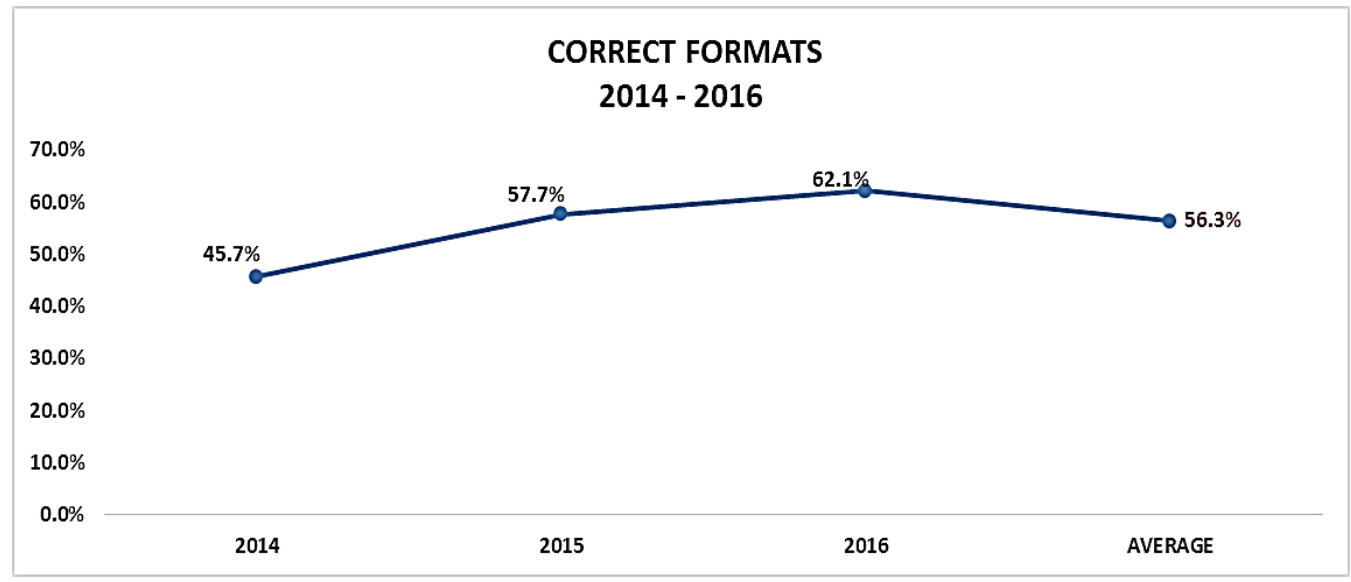

Figure 2. Evolution of correct formats

It shows an IMPROVEMENT compliance for Sign up (77.82\%), Time out (73.28\%) and Sign out $(63.10 \%)$, being the first one that has the best compliance but that do not reach the GOOD categorization. See Figure 3.

\section{\% COMPLIANCE ACCORDING PHASES SURGICAL SAFETY CHECK LIST 2014 - 2016}

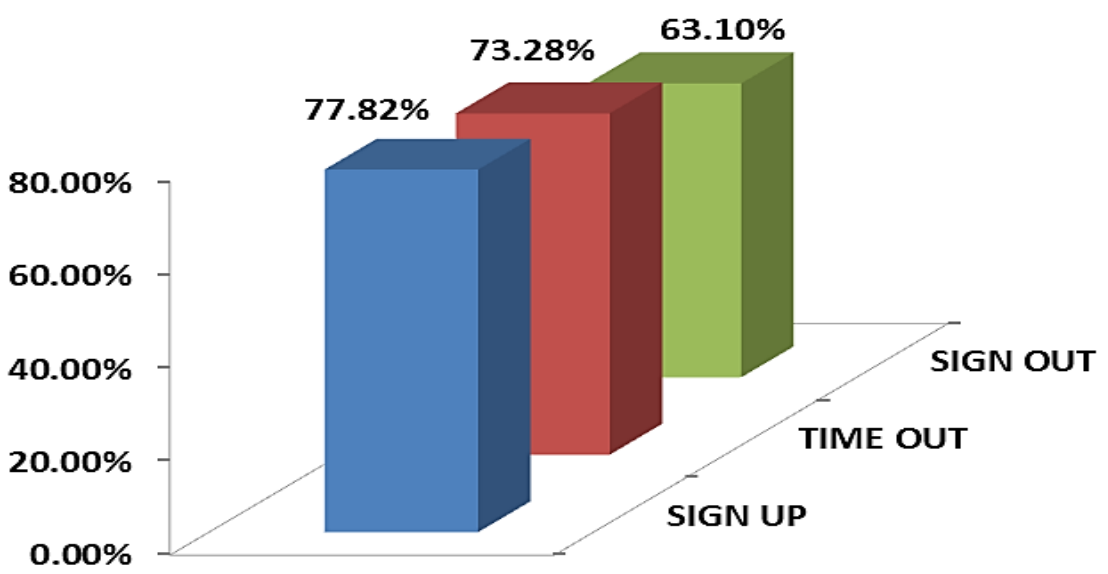

Figure 3. Compliance percentage according to phases Surgical Safety Checklist

It shows that of the total of Omissions (910) in the Sign up, Item 7 is more frequently omitted referring to the risk of bleeding $>500 \mathrm{~mL}(36 \%)$; in the Time out, Item 4 referred to the administration of prophylaxis with antibiotics in the last 60 minutes $(39 \%)$ and finally in the Sign out, Item 5 referred to the Surgeon, anesthesiologist and nurse review the critical aspects of recovery and treatment of the patient $(42 \%)$. See Figure 4. 


\section{GHM}

Vol. 2, $\mathrm{N}^{\circ} 1,2018$

Copyright @ 2018, CINCADER.

ISSN 2523-9511

\section{Journal of Global Health}

\& Medicine

\section{\% HIGHER OMISSION ITEM SURGICAL SAFETY CHECK LIST 2014-2016}

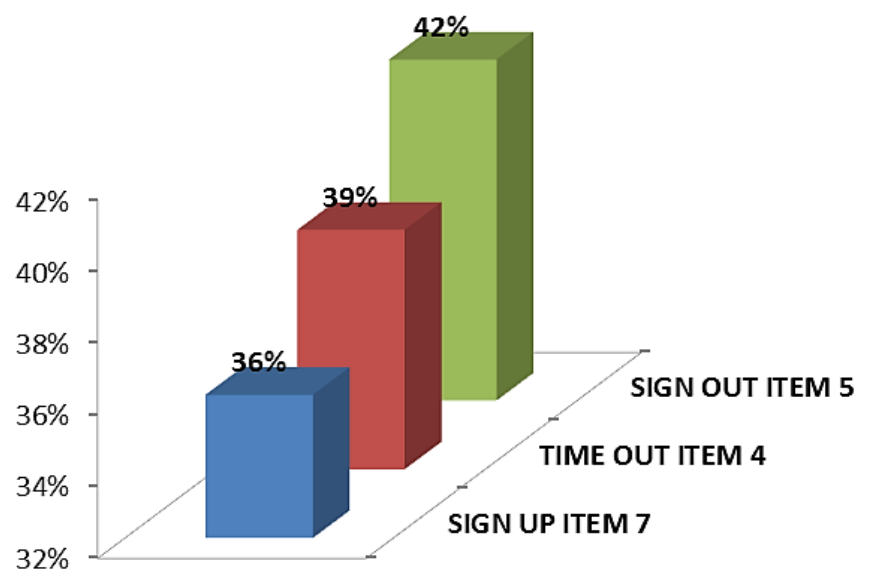

Figure 4. Higher omission item percentage from Surgical Safety Checklist

It shows the evolution of the correct seal and signature record for the operating team, reaching an upward trend of correct and complete registration (seal and signature). Being the nursing group that manages to reach $88 \%$, the Coordinator gets $64 \%$ charge also demystified by nursing, the anesthesiologist $71 \%$ and finally the surgeon $50 \%$. See Figure 5.

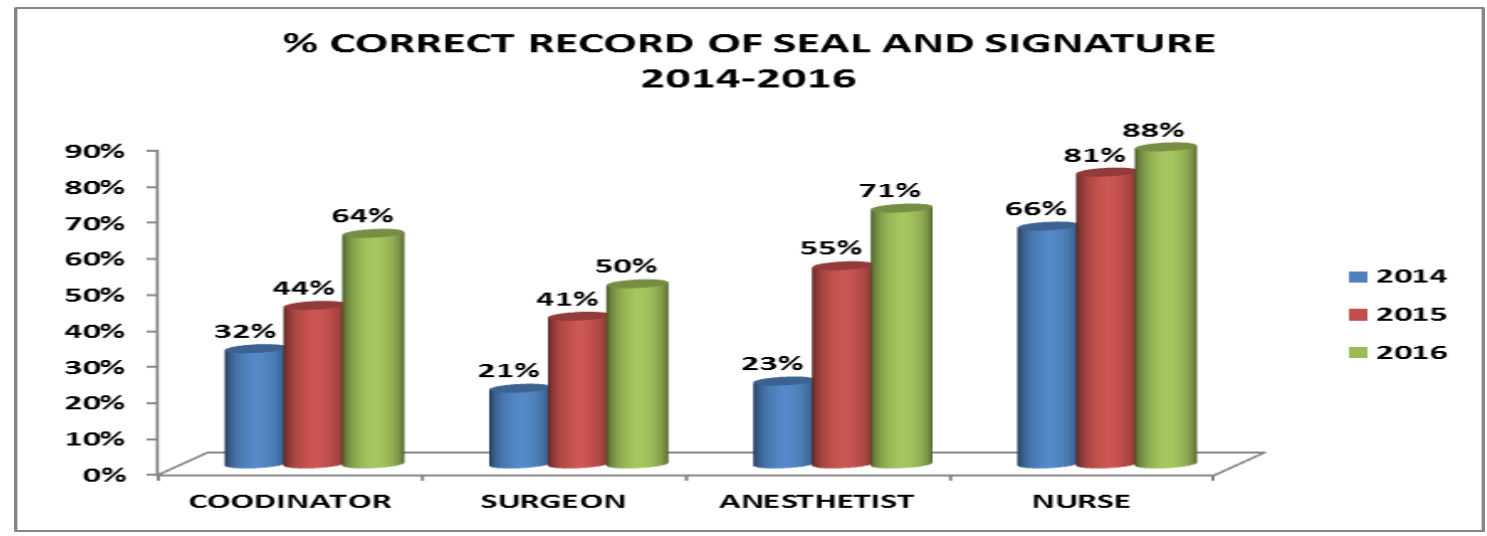

Figure 5. Correct record percentage of seal and signature.

It shows the different factor's consolidation for the implementation of the Surgical Safety Checklist where it is highlighted that the lack of staff motivation reaches $34 \%$ while the problems with the infrastructure, the lack of staff training and the Lack of knowledge of staff reach 10\%. See Figure 6. 


\section{GHM}

Vol. 2, $\mathrm{N}^{\circ} 1,2018$

Copyright @ 2018, CINCADER.

ISSN 2523-9511
Journal of Global Health

\& Medicine

Centre of Research and Training for

Regional Development Online at www.journals.cincader.org

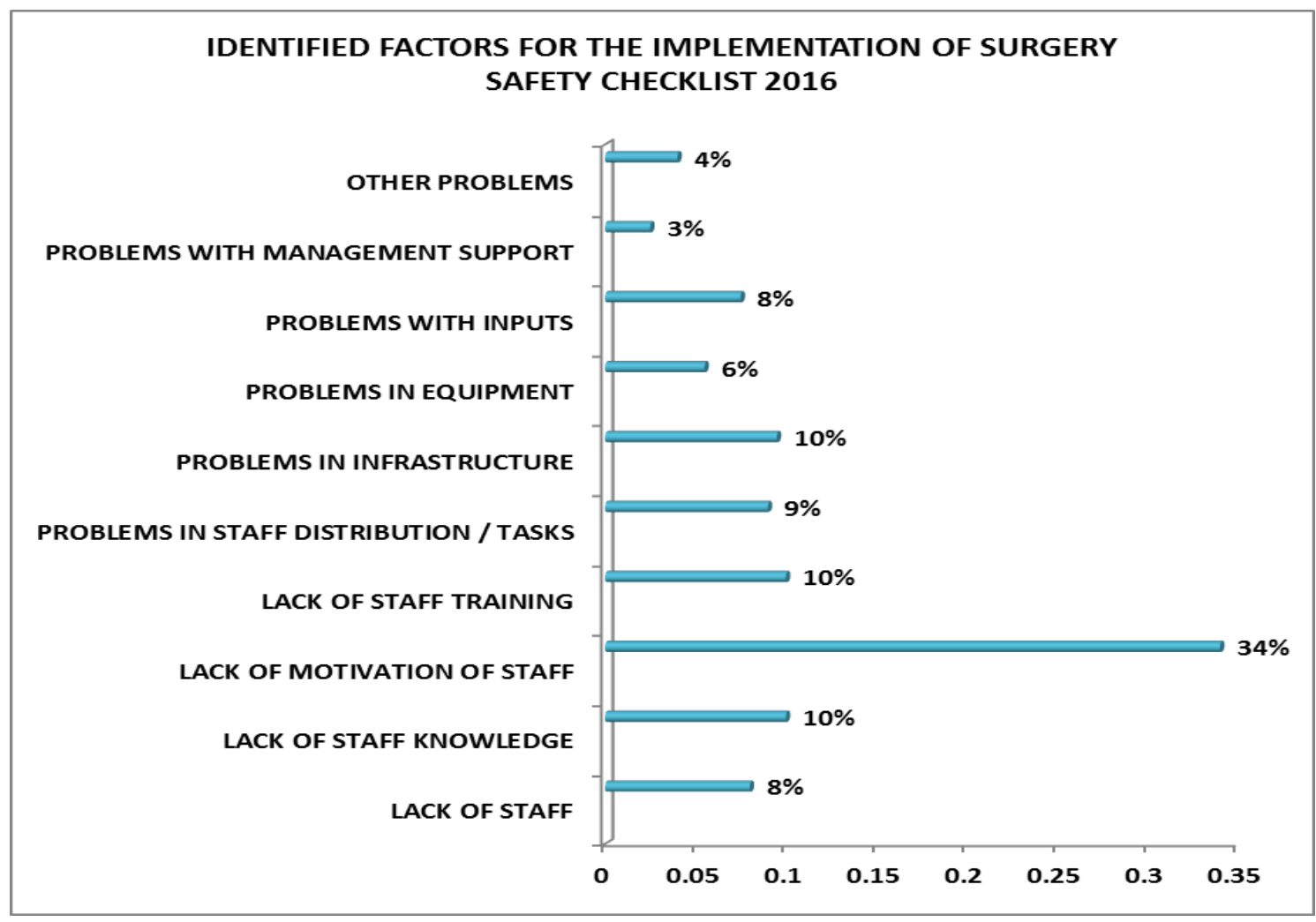

Figure 6. Identification of factors that limit its application

\section{Conclusions}

Within the institution, the Office of Quality Management of the National Hospital Arzobispo Loayza, through the patient safety unit, has the responsibility of monitoring and following up, to verify the appropriate use of this instrument according to the items requested in the Safe Surgery Verification Checklist and applied in the different operating rooms within the institution. Results are indispensables for the implementation of actions or improvement projects, which contributes to the achievement of the health objectives that guarantee the quality of attention to the user.

Whit the analysis of SSVC execution three phases, the Entrance Phase reaches $77.82 \%$ of execution, Pause a $73.28 \%$ and Exit $63.10 \%$ the respective percentages reach a categorization of TO IMPROVE. On the other hand; in the analysis of the omissions, it is evident that in the Entry Phase, the risk of haemorrhage $>500 \mathrm{~mL}$ is not marked more frequently (36\%), so the team is not identified and adequately addressed the risk of significant loss of blood. In the Pause, it is omitted to mark more frequently (39\%) the administration of prophylaxis with antibiotics in the last 60 minutes, so there is no use of systematic methods that minimize the risk of surgical site infection; noting that there is also a group of surgeries where not necessarily the administration of prophylactic applied, having made a cross-checking between the sheet Medical Therapeutics, the Nursing Kardex and the same marking item in the checklist of Safe surgery.

Finally, in the Departure, the item that is most frequently missed (42\%) is Surgeon, where anesthesiologist and nurse review the critical aspects of recovery and treatment of the patient, so it would not be communicating and effectively exchanging that information about of the patient, which is critical for the safety of the 


\section{GHM}

Vol. 2, $\mathrm{N}^{\circ} 1,2018$

Copyright (C) 2018, CINCADER.

ISSN 2523-9511
Journal of Global Health

\& Medicine

Centre of Research and Training for

Regional Development Online at www.journals.cincader.org

intervention. A correct record of the seal and signature of the professionals involved in the application of the SSVC shows that Nursing, Anesthesiology and Surgery in that order reach percentages of $88 \%, 71 \%$ and $50 \%$ respectively, being categorized all, as IN PROCESS.

In reference to the problems identified in the implementation of the SSVC, $56 \%$ of the surveyed population formulates that the assistance factor (lack of motivation) is the main cause that prevents the adequate implementation of the SSVC; while the administrative / assistance factors such as infrastructure, training and lack of knowledge in lower percentages (10\%).

\section{Reference}

[1]. WHO (World Health Organization), Guidelines for Safe Surgery, Safe Surgery Saves Lives. 2009, Available in: http://apps.who.int/iris/bitstream/10665/44185/1/9789241598552 eng.pdf

[2]. World Health Organization, World Alliance for Patient Safety. Marco conceptual de la clasificación internacional para la seguridad del paciente. Informe técnico definitivo. [Monografía en Internet]. Geneva: World Health Organization, 2009. Available in: http://www.who.int/patientsafety/implementation/taxonomy/es/index.html

[3]. Estudio IBEAS Prevalencia de efectos adversos en hospitales de Latinoamérica, 2010, Available in: http://www.msc.es/organizacion/sns/planCalidadSNS/docs/INFORME_IBEAS.pdf

[4]. Estrategia Nacional de Seguridad del Paciente del período 2005-2011, Available in: https://www.seguridaddelpaciente.es/resources/documentos/2015/Estrategia\%20Seguridad\%20del \%20Paciente\%202015-2020.pdf?cdnv=2

[5]. Perez R, Perception of the surgical team about the utility and application of the checklist of safe cardiovascular surgery in the Service of Surgical Center at the Cardiovascular National Institute of EsSalud, 2014. Available in: http://pesquisa.bvsalud.org/portal/resource/pt/biblio-871223.

[6]. DL N 1153. Normas Legales. El Peruano, 2013, Available in: http://busquedas.elperuano.pe/normaslegales/decreto-legislativo-que-regula-la-politica-integral-decompe-decreto-legislativo-n-1153-987016-1/

[7]. MINSA, Guia Técnica de implementación de la lista de verificación de la seguridad de la cirugía. 2011. Available in:

ftp://ftp2.minsa.gob.pe/descargas/calidad/normas/documentos/doc_verificacion_seguridad.pdf 